\title{
Madeleine Dreyfus: Ein ziemlich jüdisches Leben - säkulare Identitäten im Spannungsfeld interreligiöser Beziehungen (Böhlau-Verlag, Köln, 2016)
}

Berthold Rothschild (Zürich)

\begin{abstract}
Ein junger Christ hat sich in Kohns Tochter verliebt. «Einem Goj gebe ich meine Tochter nicht!', sagt der Vater. Der junge Mann unterzieht sich der Beschneidung, studiert ein volles Jahr an der Jeshiva (Talmud-Hochschule) den Talmud und meldet sich wieder. "Ich gebe Ihnen meine Tochter dennoch nicht», erklärt der Vater. «Mein Gott», jammert der Jüngling, «was soll ich jetzt tun?» «Sehr einfach», rät Kohn, «tun Sie dasselbe wie alle jungen Juden: heiraten Sie eine Schickse!» (nicht-jüdische Frau). (Aus: Landmann, 1960)
\end{abstract}

Das Buch kommt etwas gar schlicht daher, in senfgelbem Kleid und mit recht bescheidenem Titel: «Ein ziemlich jüdisches Leben». Was soll der NormalPassant, die Normal-Passantin darunter verstehen? So ganz schnell übersetzt heisst dies wohl: «Ein jüdisches Leben», aber nicht ein vollständiges, etwa wie wenn man mitteilt, heute sei ein ziemlich schöner Tag; oder meint die Autorin mit «ziemlich» so etwas wie geziemlich=schicklich, anständig, nicht anstössig, im Sinne von Goethes Tasso etwa: «Willst du genau erfahren was sich ziemt, so frage nur bei edlen Frauen an ...» (Goethe, 1790, II, 1).

Wer die Autorin Dr. phil. Madeleine Dreyfus kennt, der weiss, dass dies so wohl nicht gemeint sein kann und wird sogleich am ebenso hermetischen Untertitel «Säkulare Identitäten im Spannungsfeld interreligiöser Beziehungen» etwas ratlos weiterkauen. Leider hilft auch die Pastellzeichnung von Peter Emch auf dem Cover nicht viel weiter - sie zeigt lediglich an, es handle sich wahrscheinlich um die klammerige Verbindung zweier komplexer Strukturen. Aber wer bis jetzt nicht aufgegeben hat, wird es nicht bereuen. Denn hinter der bescheidenen Tarnung verbirgt sich ein reicher Schatz an Wissen und an Forschung, so wie es sich für eine akademische Doktorarbeit geziemt. Madeleine Dreyfus will mit der vorliegenden Arbeit etwas untersuchen, das von hoher, manchmal auch von brennender 
Aktualität ist. Ihre Arbeit ist Teil eines Schweizerischen Nationalforschungsprojekts (NFP58): «Religionsgemeinschaften, Staat und Gesellschaft / Wandel im Judentum in der Schweiz».

Als erfahrene Psychoanalytikerin und auch als engagierte und bekennende Jüdin geht Dreyfus der Frage nach, welche individuelle und soziale Bedeutung die so genannten «Mischehen» für die daran beteiligten Partner und für deren Kinder haben. Gewiss ist dies ein Problem, welches auch Angehörige anderer «geschlossener Gesellschaften» betrifft. Bei den Juden und Jüdinnen allerdings scheint die damit verbundene Belastung grösser. Sie werden in vielen jüdischen Gemeinden tendenziell gerade noch toleriert, wenn nicht gar marginalisiert. Es bilden sich eigentliche Subkulturen von «reinen» und gemischten Familien heraus, die unter traditionell-rabbinischen Definitionen oft keine Heimat finden und innerhalb der jüdischen Gemeinden nach eigenen Nischen suchen müssen. «Die Moderne mit ihren Wahlmöglichkeiten habe zu einer innerjüdischen Sektenbildung geführt», zitiert Dreyfus den Konversionsspezialisten David Ellenson. Nach wie vor aber sind die Rabbiner, die Geistlichen also, die Gatekeeper zur jüdischen Religion und sie besitzen die theologische (halachische) Definitionshoheit darüber, was und wer nun «jüdisch» sei. Dreyfus weist auf die paradoxen Elemente hin, die daraus entstehen, dass häufig auch nichtpraktizierende, areligiöse Juden und Jüdinnen dennoch (immer noch) den normativen Mythos der «jüdischen Mutter» als Identitätsbildnerin aufrechterhalten. Wenn einer der Elternpartner zum Glauben des anderen übergetreten ist, kann dies für Eltern und Kinder zu Zugehörigkeits-, resp. Orientierungsproblemen führen. «Gemischt» sind heute bereits viele Familien und besonders schwierig ist es für die so genannten «Vaterjuden» (Kinder eines jüdischen Vaters ohne jüdische Mutter), die einen besonders schweren Stand in ihrer Identitätsbildung haben. Gemischt sind heute aber auch viele Familien, deren Judentum sich nicht nur klassischerweise über die jüdisch gewordene Mutter (durch Gijur=Übertritt), sondern ebenso oft durch die Mitgliedschaft in den lokalen Gemeinden manifestiert. Übergetretene Familien sind oft religiös und gemeindekulturell aktiver als viele lupenrein Alteingesessene: Doing jewish vs. Being jewish. Anders als beispielsweise in Israel: dort ist die «jüdische Identität» politisch-national konnotiert und geschichtlich (häufig über die Shoa) definiert. Dennoch erzwingt das so genannte «Gesetz der Rückkehr» (chok haschwut, 1950) die Klärung der Frage «Wer ist Jude?»und räumt damit den rabbinischen Autoritäten kanonische Macht in einem säkularen Staatswesen ein. Schlimmer noch: eigentliche «Blutgesetze» werden zu staatspolitischen Richtlinien.
Madeleine Dreyfus gelingt es in anschaulicher Weise, das Problemfeld der zunehmenden Mischehen (in den USA waren es in den 1970er-Jahren 32\% von allen in den Jahren 1966-72 jüdisch heiratenden Personen, Dreyfus, 2016, S. 112) zu untersuchen. In Zürich z. B. haben die Übertritte seit 1904 stetig zugenommen und machten von 1980-96 fast ein Drittel aller religiösen Eheschliessungen aus (Zahlen der israelitischen Cultusgemeinde Zürich, ICZ). Diese Zahlen dürften seit der Gründung so genannter liberaler jüdischer Gemeinden in der Schweiz, welche den Übertritt deutlich freier fördern, noch wesentlich gestiegen sein.

Die Autorin berücksichtigt in der Diskussion des Themas die Aspekte von Zugehörigkeit, Identitätsbildung, Tradition, Geschichte, Sozialpsychologie und Soziologie. Sie nutzt ihre Fragestellungen auch, um, wie im Untertitel bereits angetönt, der immer wieder vorgebrachten Frage zur jüdischen Identität nachzugehen und beansprucht die Leser mit einem breit angelegten Exkurs in die jüdische Geschichte. Es bleibt aber nicht bei einer theoretischen und literaturkritischen Bearbeitung des komplexen Stoffes, sondern der Autorin gelingt es, zur Illustrierung der gegenwärtigen Situation etwa 20 Schweizer und SchweizerInnen jüdischer und nichtjüdischer Herkunft aller Schattierungen zu interviewen und gekonnt über ihre Gesprächserfahrungen zu berichten. Manchmal muten diese beinahe wie Krankengeschichten an, aber es ist daraus ein überaus reiches, manchmal sogar unterhaltsames Beobachtungsfeld entstanden. Insgesamt gestattet dies der Autorin, die Enge und Strenge der rabbinischen Auslegungen faktenreich zu dekonstruieren.

Mischehen, so ihr Fazit, seien nicht etwa - wie von vielen, vor allem ultrareligiösen Kreisen immer wieder behauptet wird - eine Gefahr für die weitere Existenz des jüdischen Volkes. Viel mehr seien sie für die Beteiligten oft eine spirituelle Bereicherung und ermöglichten eine Klärung ihres bewussten und gewollten Jüdischseins («noch in der Weise, wie man es nicht ist, ist man jüdisch», zitiert die Autorin Marthe Robert zu Kafka, S. 11). Dazu die Autorin über ihre eigene Erfahrung: «(...) dass ich mich erst am jüdischen Gemeindeleben beteiligen konnte, als ich mit meinem nichtjüdischen Mann verheiratet war. Ich fühlte mich freier, weniger beobachtet, es fiel mir plötzlich leicht, die Familientradition des hohen sozialen Engagements weiterzuführen (...)», (S. 9).

Zu Hilfe kommt ihr bei ihren Studien nicht nur ihr psychoanalytisches Wissen und ihre langjährige Berufserfahrung, sondern auch ihre breitgefächerte Kompetenz in historischer, soziologischer und kulturtheoretischer Methodik. Entsprechend ist das Buch auch mehrheitlich übersichtlich und sachkundig durchkomponiert, manchmal sogar dramaturgisch entwickelt, so dass die an sich tro- 
ckene und artefaktische Materie durchaus fesselnd und unterhaltsam zu lesen wird. Ausserdem verfügt die Rabbiner-Enkelin über ein breites und differenziertes jüdisches Wissen, welches ihren Argumenten eine unausweichliche Aussagekraft verleiht. Schade ist allerdings, dass die Autorin bei ihrem evident grossen Sachwissen gewisse Begriffe nicht genügend klärt und unterscheidet, so etwa die Begriffscluster «Assimilation-Emanzipation-Säkularisation» und schade ist auch, dass der grosse Aufwand an Interviews und theoretischer Hintergrunds- und Denkarbeit nicht auch dazu verwendet werden konnte, um die tabuisierten Bereiche homosexueller Identität bei verschiedenen Juden und Jüdinnen zu ergründen und zu beleuchten. Die Dreyfus'sche Methode würde sich dafür bestens eignen. Ein ziemlich gelungenes Buch, tatsächlich!

\section{Literatur}

Goethe, J.W. (1790). Torquato Tasso. Ein Schauspiel. Leipzig: G. J. Göschen. Landmann, S. (1960). Der jüdische Witz. Olten: Walter Verlag. 